\title{
Effects of androgens on cultured cells derived from canine anterior cruciate ligament
}

\author{
By
Hideki OHNO ${ }^{1}$, Yoko KOWATARI ${ }^{2}$, Masao OWAKI ${ }^{3}$, Joji OHTA³, Naoshi NAKAJIMA4, Kazuki YOSHIOKA ${ }^{5}$, Ken-ichiro MUTOH ${ }^{5}$ and Toshifumi OYAMADA ${ }^{5}$ \\ ${ }^{1}$ Ohno Dog and Cat Hospital, 5-2 Kurisaki, Honjo, Saitama, 367-0032, Japan \\ ${ }^{2}$ Nara Livestock Hygiene Service Center, 600-3 Tsutsui, Yamatokoriyama, Nara, 639-1123, Japan \\ ${ }^{3}$ Inuyama Animal Hospital, 29 Haguro-omishita, Inuyama, Aichi, 484-0894, Japan \\ ${ }^{4}$ Shimodate Animal Hospital, 1246-3 Shimonakayama, Chikusei, Ibaraki, 308-0825, Japan \\ ${ }^{5}$ School of Veterinary Medicine, Kitasato University, 35-1 Higashi-23bancho, Towada, Aomori, 034-8628, Japan
}

- Received for Publication, June 12, 2012 -

Key Words: Androgen receptor, Anterior cruciate ligament, Cell culture, Collagen, Fibroblast

\begin{abstract}
Summary: Anterior cruciate ligament (ACL) fibroblasts obtained from beagle dogs were cultured in basal medium containing different concentrations of 1 to $10^{-3} \mu \mathrm{M} 5 \alpha$-dihydrotestosterone (DHT) and in basal medium itself as a control. It was demonstrated that DHT promoted cell proliferation activity, expression of androgen receptor, and collagen synthesis in ACL fibroblasts as compared with control. These results suggest that sex hormones are involved in the sex difference seen in ACL rupture of dogs.
\end{abstract}

\section{Introduction}

Rupture of the anterior cruciate ligament (ACL) is one of the causes of hind limb claudication in dogs. In humans, particularly among athletes, rupture of ACL is also a common injury, and its incidence is higher in females than in males. Similar tendency is recognized in dogs and it is reported that the incidence of ACL ruptures is significantly higher in surgically spayed or neutered dogs than in intact dogs that have not undergone such surgery ${ }^{1-3)}$. While there have been many reports regarding the relationship between estrogens or progesterone and $\mathrm{ACL}^{4,5)}$, little is known about ACL's relationship with androgen. The canine ACL is an androgen-dependent tissue and we also demonstrated in vivo expression of the androgen receptor in the canine ACL (unpublished data).

However, to our knowledge, there have not been any studies that conducted to investigate the in vitro effects of androgens on the ACL. Accordingly, in this study, we examined the in vitro effects of $5 \alpha$-dihydrotestosterone (DHT) on ACL fibroblasts.

\section{Materials and Methods}

ACLs for this study were collected from two normal beagle dogs. The ligament explants were cultured in basal medium (DMEM supplemented with 15\% FBS, $250 \mu \mathrm{M}$ ascorbic acid, $200 \mathrm{U} / \mathrm{mL}$ penicillin, and $100 \mu \mathrm{g} / \mathrm{mL}$ streptomycin) following standard tissue culture procedures. DHT at concentrations of $1,10^{-1}, 10^{-2}$, and $10^{-3} \mu \mathrm{M}$ was added in the medium. The medium itself without DHT was prepared as control. ACL fibroblasts were cultured respectively for 24, 48, and 96 hours. Cultured fibroblasts were followed by fixation in paraformaldehyde and immunohistochemical staining (IHC) using primary antibodies against androgen receptor (AR), procollagen type 1 , and proliferating cell nuclear antigen (PCNA), respectively. Additional investigations of differential interference contrast imaging and MTS assay (Cell Titer 96R Aqueous OneSolutiom Cell Proliferation; Promega., Madison, WI) assay for cell proliferation measurement were performed. 


\section{Results}

Observation of canine ACL fibroblasts under the differential interference contrast microscope revealed typical fibroblast-like morphology. Cells with DHT after 48-hour treatment, fibroblasts appeared large and prominent nucleoli in their nuclei and elongated cells were observed after a 96-hour treatment (Figs. 1-4). The numbers of AR antibody-positive cells were higher in the DHT-treated groups than in controls at all time points, and the increase of AR expression level was dose-dependent after 48- and 96-hour treatments (Figs. 5-10). Regarding procollagen type 1 expression, positive level was higher in the DHTtreated groups than in controls at all time points (Figs. 11-14). While increase in the expression level by DHT treatment was dose dependent at 48 hours, the response to DHT decreased at 96 hours and no obvious difference between different concentrations was observed (Figs. 1516). The proportion of PCNA antibody-positive cells was higher in the DHT-treated groups than in controls at all time points (Fig. 17). According to MTS assay, DHTtreated groups showed a higher proliferative responses than controls at all time points $(\mathrm{p}<0.05)$ with an apparent DHT dose-dependent increase at 48 hours (Fig. 18).

\section{Discussion}

Immunohistochemical examination revealed significant and dose-dependent increases in both expressions of AR protein and procollagen type 1 of the DHT-treated groups compared with controls. This close relationship between AR expression/collagen synthesis and DHT suggests that DHT stimulates the synthesis of AR protein and simultaneously increases collagen synthesis. Generally, $\mathrm{AR}$ is known as a ligand-dependent transcription factor belonging to the nuclear receptor superfamily, and becomes functional upon high-affinity binding with biologically active androgens such as testosterone and $\mathrm{DHT}^{6}$. It is also demonstrated that the synthesis of nuclear AR is
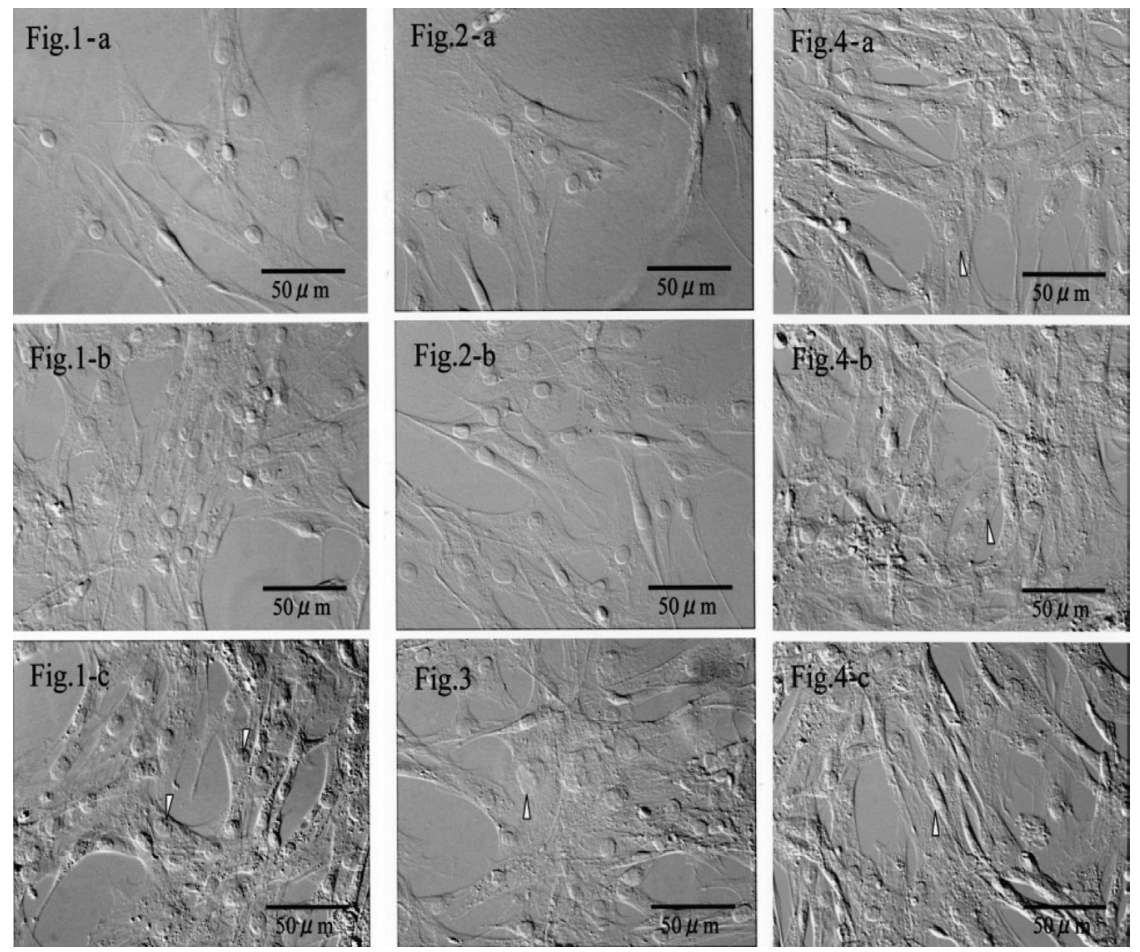

Fig. 1. Control; differential interference contrast images. 1-a: Cells contain large uniform nuclei that are round to semi-round in shape and display a flat, bidirectional and needle-shaped morphology with obscure nucleoli. 1-b: Cell density increased. Cell formed spindle-shaped and attached to each other. 1-c: Cell density increased more than Fig 1-b. Some of cells formed small nucleoli (arrowhead).

Fig. 2. DHT treatment for 24 hours; differential interference contrast images. Cells were treated with (a) $10^{-3}$ and (b) $1 \mu \mathrm{M}$ DHT. 2 -a: Cells with a short major axis are observed at 24 hours. 2-b: Mixture of cells with long and short major axes are observed and the size of their nuclei is heterogeneous at 24 hours.

Fig. 3. DHT treatment for 48 hours (with $1 \mu \mathrm{M}$ DHT); differential interference contrast images. Cells with a large nucleus (arrowhead) are observed.

Fig. 4. DHT treatment for 96 hours; differential interference contrast images. Cells were treated with (a) $10^{-2}$, (b) $10^{-1}$, and (c) $1 \mu \mathrm{M} \mathrm{DHT.} \mathrm{4-a:} \mathrm{Large}$ cells (arrowhead) are observed. 4-b: A large number of small cells (arrowhead) are observed. 4-c: Cells with an oval nucleus (arrowhead) are observed. 


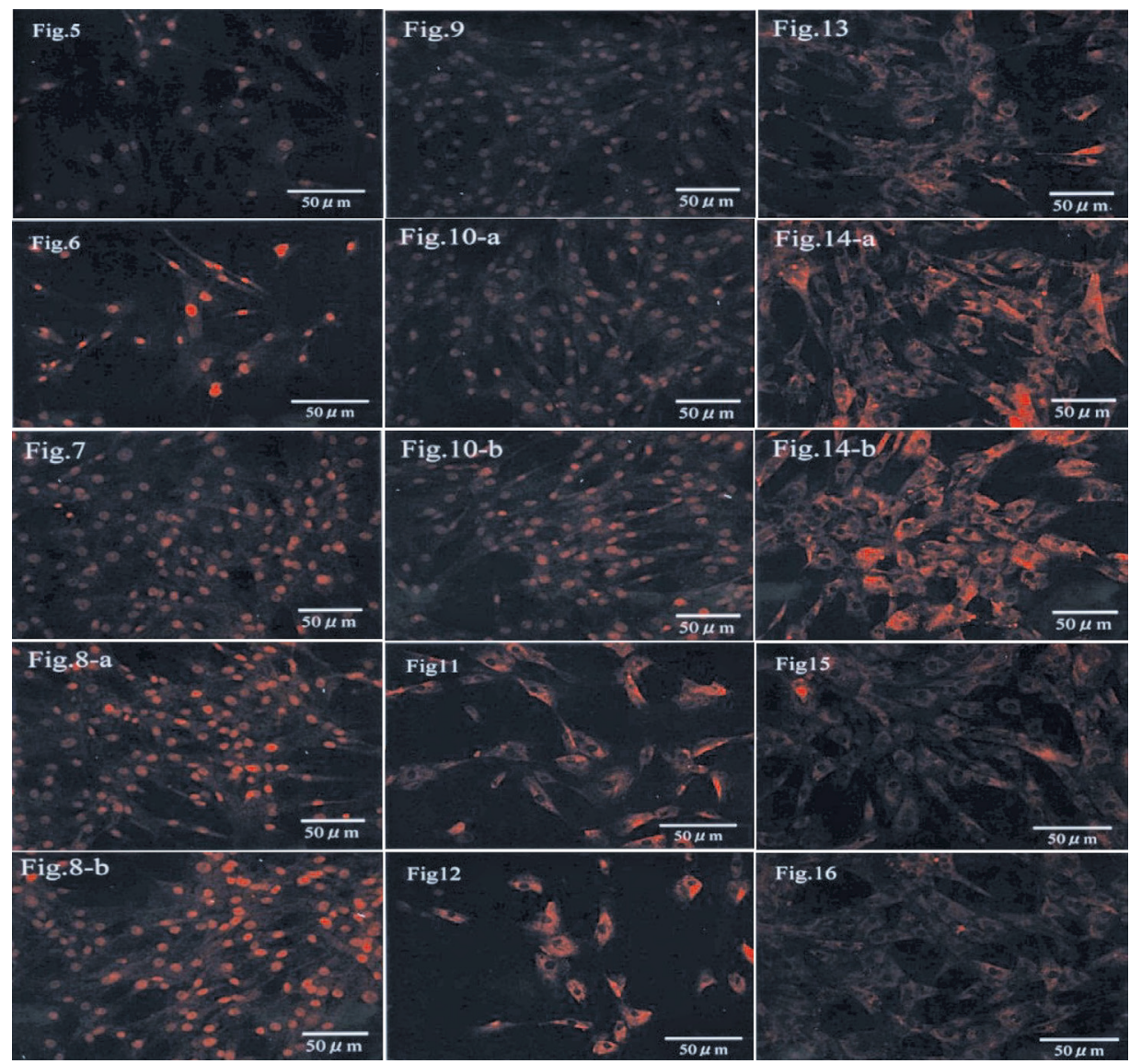

Fig. 5. Control. (24-hour); IHC for AR. The level of expression of AR detected by the anti-AR antibody was generally weak with no positive cells. Fig. 6. DHT-treated cells (24-hour treatment with $10^{-2} \mu \mathrm{M}$ DHT); IHC for AR. Cells are strongly positive compared with the control.

Fig. 7. Control. (48-hour); IHC for AR. The level of expression is weak in the majority of the cells with few positive cells. Cells were treated with (a) $10^{-2} \mu \mathrm{M}$ and (b) $1 \mu \mathrm{M}$ DHT. A slight increase in the expression level is observed dose dependently, even though the expression level is generally lower than at 48 hours.

Fig. 8. DHT-treated cells (48-hour treatment); IHC for AR. Cells are treated with (a) $10^{-2} \mu \mathrm{M}$ and (b) $1 \mu \mathrm{M}$ DHT. A dose-dependent increase in the number of strongly positive cells is observed.

Fig. 9. Control. (96-hour treatment); IHC for AR. The expression level is generally weak with no positive cells.

Fig. 10. DHT-treated cells (96-hour treatment); IHC for AR. Cells are treated with (a) $10^{-2} \mu \mathrm{M}$ and (b) $1 \mu \mathrm{M}$ DHT. A slight increase in the expression level is observed dose dependently, even though the expression level is generally lower than at 48 hours.

Fig. 11. Control. (24-hour); IHC for procollagen type 1. Cells are only weakly positive.

Fig. 12. 1- $\mu \mathrm{M}$ DHT-treated cells (24-hour treatment); IHC for procollagen type 1. Cells are stronger positive than at control.

Fig. 13. Control. (48-hour); IHC for procollagen type 1. Cells are only weakly positive.

Fig. 14. DHT-treated cells (48-hour treatment); IHC for procollagen type 1. Cells are treated with (a) $10^{-2} \mu \mathrm{M}$ and (b) $1 \mu \mathrm{M}$ DHT. A dose-dependent increase is observed in the intensity.

Fig. 15. Control. (96-hour); IHC for procollagen type 1. The intensity become weaker than expression level of positive cells at 48 hours.

Fig. 16. DHT-treated cells (96-hour treatment with $10^{-2} \mu \mathrm{M}$ DHT); IHC for procollagen type 1 . The responsiveness is attenuated at 96 hourtreatment with no obvious difference between different concentrations.

stimulated by DHT with a DHT dose-dependent manner ${ }^{7}$. Promotion of collagen synthesis by DHT has been reported on the studies of cultures of rat osteocytes ${ }^{8}$ and human osteoblast. Also morphologically, differential interference contrast images showed DHT-treated ACL fibroblasts were in active stage. It means ACL is engaged in the AR protein and collagen synthesis. By morphometric examination, PCNA-positive cells in the DHT-treated groups were increased in number after 8- and 96-hour treatments compared with the controls. These observations suggest that DHT stimulates cell proliferation to ACL fibroblasts. Enhanced cell proliferation by DHT has been reported in normal gingival fibroblasts by Coletta et al. (2002) $)^{9}$.

On the other hand, AR protein expression increased after a 24-hour DHT treatment compared with controls and the increase was dose-dependent at 48 hours. On 


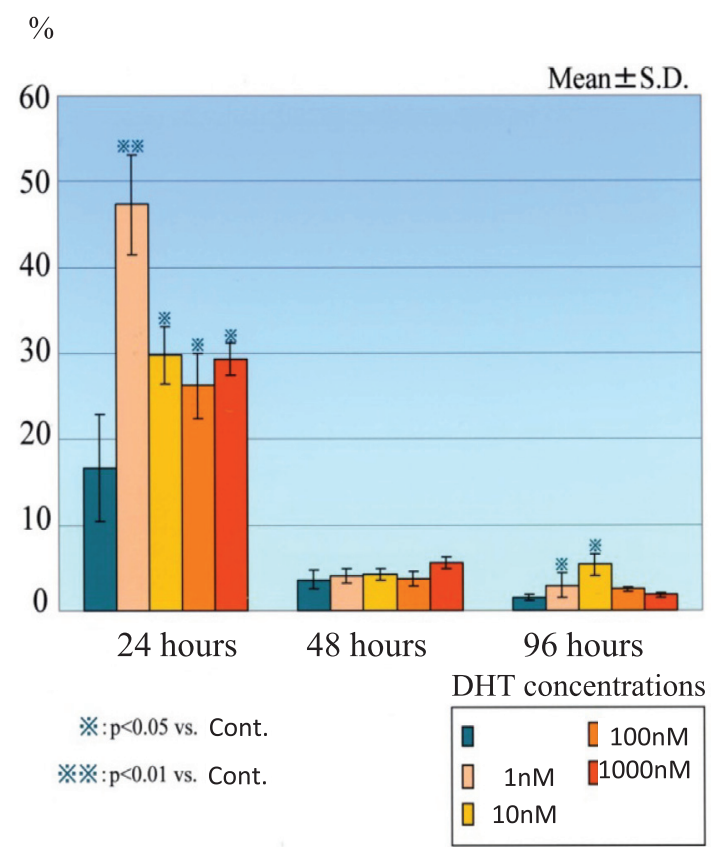

Fig. 17. PCNA-positive rates of cultured cells.

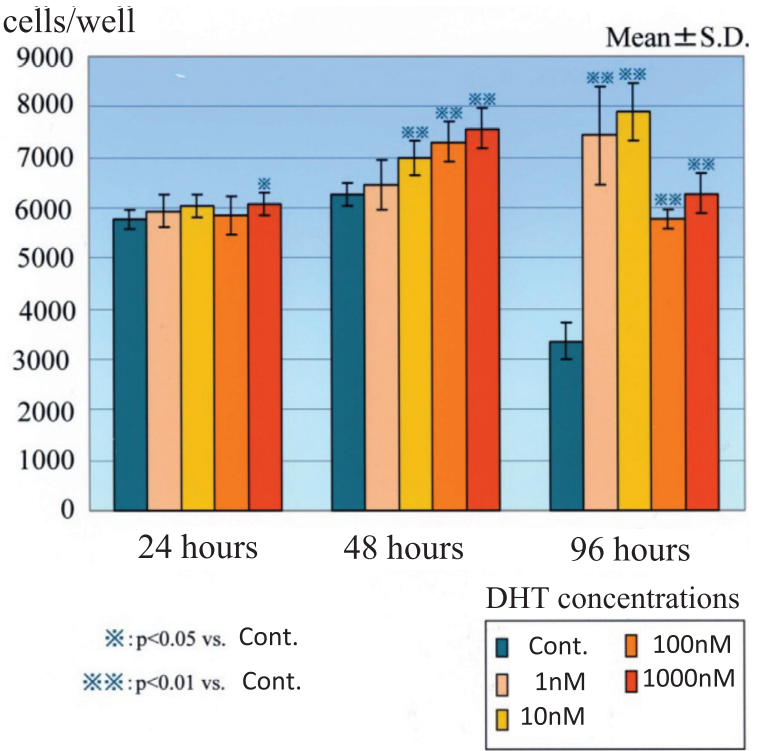

Fig. 18. Cell proliferation activity of cultured cells.

\section{References}

differential interference contrast microscope observation, nucleoli of ACL fibroblasts were clearly observed after treatments of 48 hours and longer, but were not observed after a 24-hour treatment. In addition, the MTS assay for cell proliferation demonstrated a noticeable increase in the cell counts after treatments of 48 hours or longer, although no difference was observed after a 24-hour treatment. Since synthesis of AR is known to occur before cell proliferation and DNA synthesis ${ }^{7}$, it is suggested that the majority of the cells were in a pre-DNA synthesis state in the 24 hours from the beginning of treatment, and this resulted in the difference in the AR expression alone without a significant increase in the cell counts. Mitosis was presumably complete in many cells after at least 48 hours, resulting in the emergence of nucleoli and increase in the cell counts. Based on the in vitro study on prostate glands in castrated rats, significant increases in DNA synthesis and cell production 24 to 36 hours after administration of DHT in comparison with the control animals were reported ${ }^{10)}$. The evidence of the present study suggests that DHT acts on the ACL fibroblasts to increase AR expression and enhance collagen synthesis, as well as to promote cell proliferation. Additionally, DNA synthesis in the ACL fibroblasts and cell division upon stimulation by DHT likely occurs between 24 and 48 hours after the beginning of DHT treatment.

1) Duval JM, Budsberg SC, Flo GL, Sammarco JL: Breed, sex, and body weight as risk factors for rupture of the cranial cruciate ligament in young dogs. J Am Vet Med Assoc 1999; 215:811-814.

2) Slauterbeck JR, Pankratz K, Xu KT, Bozeman SC, Hardy DM: Canine ovariohysterectomy and orchiectomy increases the prevalence of ACL injury. Clin Orthop Relat Res 2004; 429:301-305.

3) Whitehair JD, Vasseur PB, Willits NH: Epidemiology of cranial cruciate ligament rupture in dogs. J Am Vet Med Assoc 1993; 203:1016-1019.

4) Lovering RM, Romani WA: Effect of testosterone on the female anterior cruciate ligament. Am J Physiol Regul Integr Comp Physiol 2005; 289:R15-22.

5) Yu WD, Liu SH, Hatch JD, Panossian V, Finerman GA: Effect of estrogen on cellular metabolism of the human anterior cruciate ligament. Clin Orthop Relat Res 1999; 366:229-38.

6) Lee HJ, Chang C: Recent advances in androgen receptor action. Cell Mol Life Sci 2003; 60:1613-1622.

7) Van Doorn E, Craven S, Bruchovsky N: The relationship between androgen receptors and the hormonally controlled responses of rat ventral prostate. Biochem J 1976; 160:11-21.

8) Gray C, Colston KW, Mackay AG, Taylor ML, Arnett TR: Interaction of androgen and 1, 25-dihydroxyvitamin D3: effects on normal rat bone cells. J Bone Miner Res 1992; 7:41-46.

9) Coletta RD, Reynolds MA, Martelli-Junior H, Graner E, Almeida OP, Sauk JJ: Testosterone stimulates proliferation and inhibits interleukin-6 production of normal and hereditary gingival fibromatosis fibroblasts. Oral Microbiol Immunol 2002; 17:186-192.

10) Lesser B, Bruchovsky N: The effects of testosterone, 5-dihydrotestosterone and adenosine 3', 5'-monophosphate on cell proliferation and differentiation in rat prostate. Biochem Biophys Acta $1973 ; \mathbf{3 0 8 : 4 2 6 - 4 3 7 . ~}$ 